\title{
RESEARCH
}

Open Access

\section{Prevalence of short stature and malnutrition among Egyptian primary school children and their coexistence with Anemia}

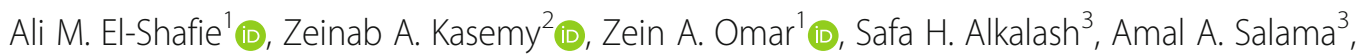
Kerollos S. Mahrous ${ }^{1,4^{*}}$ D, Shaimaa M. Hewedy ${ }^{5}$, Nessreen M. Kotb ${ }^{5}$, Heba S. Abd El-Hady ${ }^{5}$, Eman S. Eladawy ${ }^{5}$, Mohamed A. Zeid ${ }^{5}$, Manar E. Abd El Hamid ${ }^{5}$, Emad H. Hemeda ${ }^{5}$, Mohamed A. El-shafie ${ }^{5}$, Esraa A. El-Meligy ${ }^{5}$ and Wael A. Bahbah' (D)

\begin{abstract}
Background: Under nutrition and overweight typically occur during nutritional transition periods in developing countries including Egypt. Short stature and anemia are public health concern due to its strong link with malnutrition which is a preventable risk factor.
\end{abstract}

Objectives: to estimate the prevalence of overweight, obesity, underweight and short stature and its concurrence with anemia, also to determine the etiological profile of short stature among primary school children in Egypt.

Methods: A cross-sectional study was carried out on 33,150 Egyptian children aged 6-11 years old from January 2018 to January 2020, allocated in 59 primary schools from diverse geographical districts in Egypt. Complete anthropometric measurements were conducted and applied according to WHO growth charts. Hemoglobin level was measured. Systematic approach to detect the etiology of short stature was applied randomly to a sample of 380 stunted children.

Results: The prevalence of underweight was 8.2\%, while obesity and overweight represented $21.8 \%$ (9.6 and 12.2\% respectively). Overall short stature constituted $17 \%$. The main etiologies of short stature were familial (40.8\%) and constitutional (24.2\%). Anemia was diagnosed in $26 \%$ of children; while concurrent anemia and stunting was reported in 9.9\%. Regarding anemia and anemia with stunting were more common among girls (30.0\% (OR $=1.50$, Cl95\%: 1.43-1.58) and $11.4 \%(\mathrm{OR}=1.39, \mathrm{Cl} 95 \%: 1.29-1.49)$ respectively), who were living in rural areas (33.4\% (OR= 1.96, Cl 95\%:1.87-2.06) \&12.7\% (OR=1.72, Cl 95\%:1.60-1.85)) and those who had low socioeconomic status)34.6\% $(\mathrm{OR}=2.54, \mathrm{Cl} 95 \%: 2.29-2.82) \& 17.2 \%(\mathrm{OR}=3.32, \mathrm{Cl} 95 \%: 2.85-3.88()$ respectively. Anemia with stunting was significantly higher among children aged $\geq 9$ years old representing $12 \%(\mathrm{OR}=1.40, \mathrm{Cl}$ 95\%:1.30-1.51).

\footnotetext{
* Correspondence: kerosmn1@gmail.com

'Department of Pediatrics, Faculty of Medicine, Menoufia University, Shebin

El-Koum, Egypt

${ }^{4}$ Shebin El-Koum, Menoufia, Egypt

Full list of author information is available at the end of the article
}

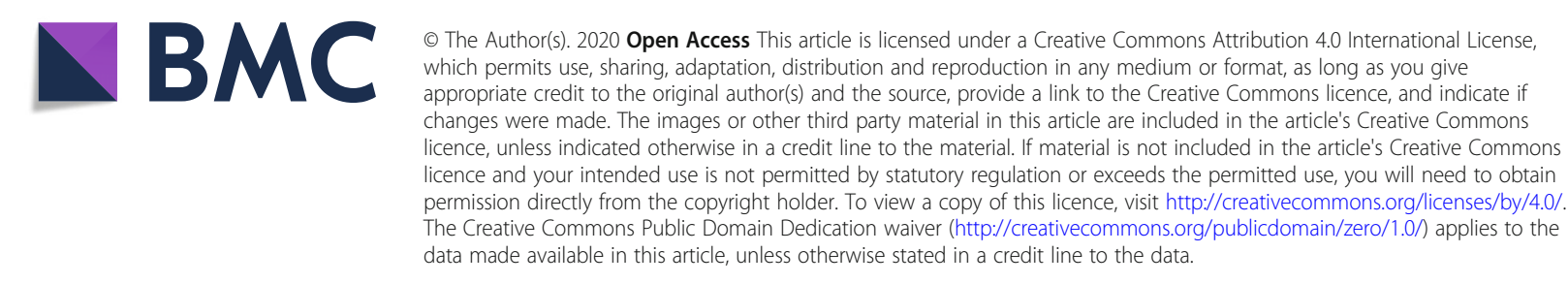


(Continued from previous page)

Conclusion: Prevalence of short stature, obesity and anemia was high among primary school children in Egypt

with a strong concurrence between anemia and stunting. Intensive parental health education and in-depth

nutritional assessment are required.

Keywords: Anemia, Egyptian children, Malnutrition, Obesity, Prevalence, Short stature

\section{Background}

The double burden of malnutrition is defined by coexistence of both under nutrition and overweight with increasing risk of non-communicable diet related diseases [1]. It is a global challenge affecting all over world countries with higher burden on underdeveloped and developing countries [2]. The causes may be related to a sequence of epidemiological changes known as nutritional, epidemiological and demographic transition and it confers a negative impact on economy of individuals and populations [3, 4]. In Egypt two thirds of under 5 years child mortality owed to malnutrition and stands as one of the 36 countries where $90 \%$ of the global burden of malnutrition falls [5]. Pediatric overweight and obesity are considered the most prevalent nutritional disorder among both children and adolescents with $21-24 \%$ of them are overweight [6]. They increase the risk of heart diseases, insulin resistance and diabetes (type 2), hyperlipidemia, hypertension, kidney and liver diseases and reproductive dysfunction [6]. WHO has reported rapid increase in their prevalence among all pediatric age groups [7]. Short stature is defined as a height that is 2 standard deviations (SD) or more below the mean height for individuals of the same sex and chronologic age in a given population [8]. Short stature, also called stunting frequently misinterpreted as a proxy indicator for malnutrition; malnutrition may lead to stunting, but stunting itself does not indicate malnutrition $[9,10]$. Most children with short stature have normal variants such as familial short stature, constitutional delay of growth and puberty, or idiopathic short stature while the most common pathological etiologies are growth hormone deficiency (GHD), hypothyroidism, celiac disease, and Turner syndrome, other causes include renal, hepatic, and gastrointestinal diseases, and other genetic syndrome [11]. Stunting often goes unrecognized in communities where short stature is the norm; On the other hand it may be the first presentation of underlying disease or health problem and it is considered a cyclical process, creating an intergenerational cycle of poverty that is difficult to break [12,13]. Underweight in a child with short stature suggests a systemic illness or malnutrition, whereas overweight suggests an endocrine disorder; if the initial evaluation suggests a genetic, endocrine, or gastrointestinal disorder [14]. Anemia is a global problem affecting around 305 million school children aged 5-15 years and it is 3-4 times more prevalent in non-industrialized regions than industrialized ones [15]. In spite of high correlation between anemia and nutrient deficiency which represents more than half of causes, but different varieties of hemoglobinopathies and chronic hemolytic anemia are worthy of research especially in geographic areas of high frequency $[15,16]$. As each of anemia and stunting represent a significant burden and challenge to the health system of children, their concurrence would be even more disastrous [17]. The aim of this work was to estimate the prevalence of overweight, obesity, underweight and short stature and its concurrence with anemia, also to determine the etiological profile of short stature among primary school children in Egypt.

\section{Methods}

A multistage random sampling technique was used to randomly select a cross-sectional study sample from a stratified listing of Egyptian primary school children aged 6-11 years, available at the time of study design. The study sample was determined based on the Egypt demographic health survey 2015 [18]. All details of the selected schools in cities and villages in every single governorate were provided. The process was totally computerized. A total national sample of 33,354 children was eligible for the study. The exclusion criteria were applied to 154 children leaving 33,150 children as a final total sample to be included in the study. The study was carried out in a time frame from the beginning of January 2018 till the end of January 2020 at 59 primary schools. (Figure 1) All types of schools (public, private and language schools) were included. All the socioeconomic strata were represented with weighted rural-urban representation. Two full-days' workshop training was provided to field work team consisted, primary care physicians, pediatricians and nurses. Workshop training was conducted in each of the chosen 7 governorates of Egypt with providing more sessions to the teams of large regions. A pilot study of 50 children was designed to test all items of the project and also to test and standardize the capabilities of the involved team before proceeding to the main data collection. The field work included the school health supervisor, field team supervisors, doctors and nurses. The trained team made visits to all selected schools to complete a socio-demographic questionnaire, 


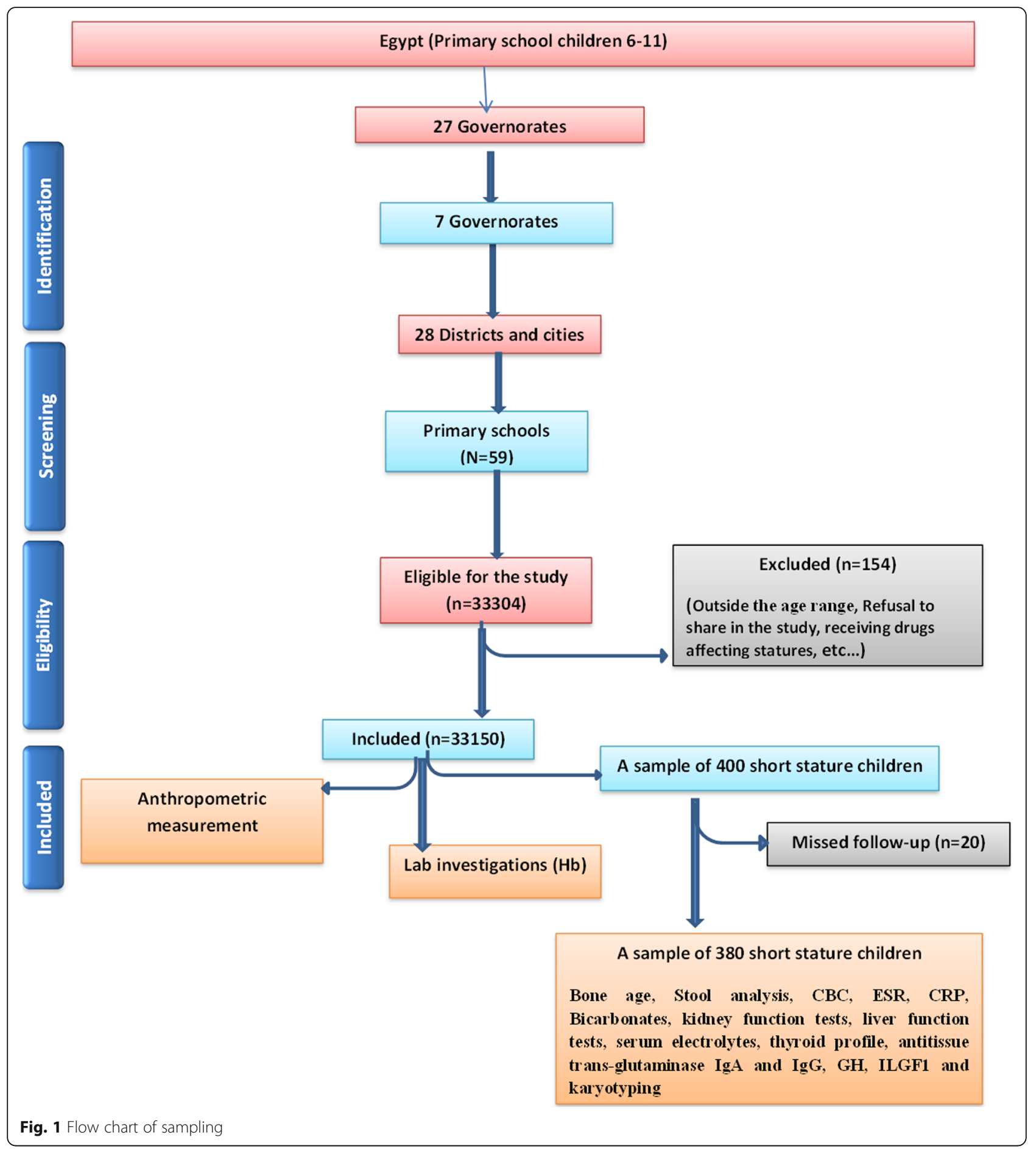

provide clinical examination and take body measurements. Children were sent to a chosen standardized laboratory center in every studied region to provide blood and stool sample to be examined.

\section{Inclusion and exclusion criteria}

Recruitment for the study was based on following inclusion criteria: Egyptian children of both sexes, aged from 6 to 11 years. The exclusion criteria were: children less than 6 years or more than 11 years old, children whose mothers/guardians or caregivers refused medical examination and investigation, receiving drugs known to cause short stature including chronic use of steroids, attention-deficit/hyperactivity disorder medications and anticonvulsants during the time of examination. 
The mother/guardian or caregiver of each participating child was interviewed for potential determinants of child nutritional status including socio-demographic characteristics. Socioeconomic standard (SES) was assessed by updated scaling score of SES developed by Fahmy et al., 2015 [19]. Physical assessment and hemoglobin $(\mathrm{Hb})$ level assessment were carried out to all children.

\section{Measurements}

Each child was instructed to stand on the center of a digital balanced scale (Beurer model GS 11, Germany) for measuring the weight and height assessed by Harpenden fixed stadiometer. Weight and height of each child was measured after calibrating to the nearest $0.1 \mathrm{~kg}$ and $0.1 \mathrm{~cm}$, respectively. Horizontal Frankfurt plane with occiput, shoulder, buttocks, and heel touching the wall and the arms was down and relaxed. Each child was measured while wearing light clothes after removing shoes, belt, cap, hair style or any other material that could interfere with their actual height and weight. Body mass index (BMI) was calculated according to equation "(weight (in kg)/height squared (m2)". Each of the three measurements was applied to WHO 2007 standard deviation growth charts [20]. Anthropometric data on the height for age of children is used to quantify stunting. A child is stunted if their height for age $\mathrm{Z}$ score (HAZ) is $<2$ SD below the WHO median where the HAZ of child $\mathrm{i}$ is measured as HAZij $=\mathrm{hij}-\mathrm{h}-\mathrm{j} / \sigma \mathrm{j}$ where hij is the height of child $i$ in group j; where the group is based on the child's sex and age. $\mathrm{h}-\mathrm{j}$ is the median height of group $j$ in the new WHO reference population and $\sigma j$ is the standard deviation value of group $\mathrm{j}$ in the new WHO reference population [20]. Two dates were so important for the determination of the exact age at the time of measurement, the exact birth date (day/month/year) from an official document and the exact date of body measurements.

\section{Laboratory investigations}

Students were subjected for anemia screening using the HemoCue (HemoCue ${ }^{\circ} \mathrm{Hb}$ 201+) photometer. Hemoglobin concentration was read to the nearest $0.1 \mathrm{~g} / \mathrm{dL}$. Children with blood hemoglobin concentration level $<11.5 \mathrm{~g} / \mathrm{dL}$ were considered anemic according to age specific cut off levels established by WHO [21].

\section{Assessment of stunted children}

Based on a past review of literature reported that the percentage of familial cause of stunting was 38\% [22]. Sample size has been calculated using the following equation: $n=\left(\mathrm{z}^{2} \times \mathrm{p} \times \mathrm{q}\right) / \mathrm{D} 2$ at CI $95 \%$ and it was 356 . To avoid drop out, 400 children with short stature were selected randomly for follow-up for a year. Twenty stunted children were missed during follow-up leaving 380 children. A specific approach inspired from consensus of European Society for Pediatric Endocrinology 2008 was followed to assess the etiological profile of stunting [8]. A high specialty center was chosen to ensure presence of all required laboratory investigations and to avoid annoying the children by stressful transportation to many places. The initial evaluation included an accurate height measurement, detailed medical and nutritional history, birth weight, physical examination in addition to family history of short stature and pubertal age of both parents. Target height was calculated by the method of mid-parental height, the average of the mother's and father's height $\pm 6.5 \mathrm{~cm}$ (addition in boys or subtractions in girls) [8]. Then calculation of the growth velocity was performed after 1 year follow up of their height, which considered normal when it is at least $4 \mathrm{~cm}$ per year [23]. All stunted children were investigated for bone age by radiography, and then assessed by radiologist according to published standards of Greulich and Pyle's atlas of skeletal development [24]. Stunted children who had decreased growth velocity, symptoms of pathological disorders or severely stunted were investigated for: Stool analysis, complete blood count (CBC), erythrocyte sedimentation rate (ESR), C-reactive protein (CRP), kidney function tests, liver function tests, serum electrolytes (calcium, phosphorus and alkaline phosphatase), bicarbonate, thyroid profile (Thyroid stimulating hormone (TSH), free thyroxin (T4)) and anti-tissue trans-glutaminase IgA and IgG (cases which tested positive were confirmed by endoscopic biopsy for celiac disease). After exclusion of other causes of short stature and systemic diseases with high clinical suspicion of GHD (height $<-3$ S. D from mean or height $\leq 2 \mathrm{~S}$. D of the corrected mid-parental height and delayed maturation of bone), Growth hormone (GH) levels (after appropriate provocation test) and insulin like growth factor-1 (IGF-1) were investigated. GHD was diagnosed when $\mathrm{GH}$ peak level is under $10 \mathrm{ng} / \mathrm{l}$ and low IGF-1 [23]. Karyotyping was done for severe stunted female (< - 3 SD.) without other causes even if no specific stigmata for Turner syndrome [8]. Idiopathic cause was diagnosed when child with short stature, a subnormal growth velocity, delayed bone age, no other medical cause, and normal provocative test of growth hormone [25].

Only data relevant to each child were entered in record then questionnaires containing sociodemographic data together with added laboratory investigations and findings of clinical examination were reviewed for completeness by the investigators. Dealing with any missing, unclear or incomplete data were done accordingly with the regional and field supervisor. 


\section{Patient and public involvement}

This work aimed to screen the prevalence of short stature, malnutrion and anemia among Egyptian primary school children. To improve the relevance of research, research oriented to mothers and the public. The interviewed mothers recommended generalizing the screening over a large population and conducting it in the most crowded districts. Hence we asked them to tell every mother in their residence areas to communicate with their regional family health facilities and asking for simple growth monitoring of their children to early detect if there are any deviation in their children growth to be early corrected. A special day per governorate had been organized to thank all participants, disseminate the results and provide an in-depth group health education session. For other mothers, the main aim of the health education session was to correct wrong information and to build knowledge base for new mothers so they know well basics of proper nutrition.

\section{Statistical analysis}

Analysis of data was done using the Statistical Package for Social Sciences ${ }^{\mathrm{TM}}$ (Version 22.0; IBM Corp., Armonk, NY, USA). Frequency was used to describe the characteristics of the study population and to estimate the prevalence of underweight, overweight, obesity, anemia and short stature. Chi-square test was used for categorical variables. $\mathrm{OR}=\mathrm{ad} / \mathrm{bc}$ was applied to assess degree of risk where $\mathrm{OR}=1 \rightarrow$ nil, $\mathrm{OR}>1 \rightarrow$ risky exposure, $\mathrm{OR}<$ $1 \rightarrow$ Protective exposure. $P$-value $<0.05$ was set to be significant.

\section{Results}

A total national sample of 33,150 children aged 6-11 years old were enrolled in the study with nearly equal male and female percentage. Other demographic characteristics of the studied participants were included in Table 1. BMI was calculated and the results revealed that Overweight and obesity represented $21.8 \%(9.6 \%$ obese and $12.2 \%$ overweight) while $8.2 \%$ of the children were underweight. Height of the participants was measured and the results showed that short stature was reported among $17 \%$ of the studied children while tall stature was reported in $3.9 \%$. With studying prevalence of short stature among obese children it was found that only $0.9 \%$ of them showed stunted growth. The current study revealed that prevalence of anemia among primary school children was $26 \%$ while anemia with stunting was reported among $9.9 \%$ of the total studied sample (which accounted of $58.1 \%$ of stunted children).

The etiology of short stature was distributed as; non pathological causes [familial (40.8\%), constitutional (24.2\%), idiopathic (6.6\%)], Malnutrition (6.8\%), endocrinal causes [Hypothyroidism (7.6\%), growth hormone
Table 1 Demographic characteristics of the studied participants

\begin{tabular}{lll}
\hline & \multicolumn{2}{l}{ Participants (No. =33,150) } \\
\cline { 2 - 3 } & no & $\%$ \\
\hline Age $(\mathbf{Y})$ & & 66.3 \\
$<9$ & 21,989 & 33.7 \\
$\geq 9$ & 11,161 & \\
Sex & & 51.7 \\
Male & 17,143 & 48.3 \\
Female & 16,007 & \\
Residence & & 56.9 \\
Urban & 18,858 & 43.1 \\
Rural & 14,292 & \\
SES & & 13.1 \\
Low & 4315 & 75.3 \\
Moderate & 24,970 & 11.6 \\
High & 3865 & \\
\hline
\end{tabular}

deficiency (9.7\%)], Systemic non endocrinal causes [(celiac disease (3.4\%), chronic kidney disease (0.5\%)] and Turner Syndrome (0.3\%). (Table 2) On studying distribution of height and BMI regarding demographic data among the studied participants; it was shown that there were highly statistically significant differences between both of them and children age, sex, residency and their socioeconomic status as it was found that $25.2 \%$ of children aged $\geq 9$ years were stunted and $25.4 \%$ of children $\geq 9$ years were overweight/obese, male children showed more stunting (19.2\%) and females were more overweight $(25.8 \%)$, also children from rural areas recorded more percentages of stunted growth (18.3\%) while (27.1\%) of urban children showed overweight/obesity. Low SES was associated with stunting (29.7\%) while high

Table 2 Etiology of short suture among studied children ( $N=$ 380)

\begin{tabular}{lll}
\hline Etiology of short suture & $N=380$ & $\%$ \\
\hline Non pathological variants: & 155 & 40.8 \\
- Familial & 92 & 24.2 \\
-Constitutional & 25 & 6.6 \\
-idiopathic & & \\
Endocrinal causes: & 37 & 9.7 \\
-GHD & 29 & 7.6 \\
-Hypothyroidism & 26 & 6.8 \\
-Malnutrition & & \\
Systemic non endocrinal causes: & 13 & 3.4 \\
-Celiac disease & 2 & 0.5 \\
-CKD & 1 & 0.3 \\
-Turner syndrome &
\end{tabular}

${ }^{\mathrm{a}} C K D$ chronic kidney disease, ${ }^{\mathrm{b}} \mathrm{GHD}$ growth hormone deficiency 
SES was associated with overweight and obesity (25.5\%). (Table 3) Regarding distribution of anemia and anemia with stunting in relation to demographic data among the studied participants, there was statistically significant differences as regards children age, sex, residency and their socioeconomic status. Regarding anemia and anemia with stunting were more common among girls $(30.0 \%$ $(\mathrm{OR}=1.50$, CI95\%: $1.43-1.58)$ and $11.4 \%(\mathrm{OR}=1.39$, CI95\%:1.29-1.49) respectively), who were living in rural areas $(33.4 \% \quad(\mathrm{OR}=1.96, \quad \mathrm{CI} \quad 95 \%: 1.87-2.06) \quad \& 12.7 \%$ $(\mathrm{OR}=1.72$, CI 95\%:1.60-1.85) $)$ and those who had low socioeconomic status) $34.6 \%$ (OR $=2.54$, CI 95\%:2.29_ $2.82) \& 17.2 \%(\mathrm{OR}=3.32$, CI 95\%:2.85-3.88() respectively. Children aged $<9$ years old showed higher prevalence of anemia $27.3 \%(\mathrm{OR}=1.23$, CI $95 \%: 1.17-1.30)$ while anemia with stunting was significantly higher among children aged $\geq 9$ years old representing 12\% $(\mathrm{OR}=1.40$, CI 95\%:1.30-1.51) (Table 4).

\section{Discussion}

In this study, the prevalence of short stature was about $17 \%$. It is much lower than figures reported in crosssectional studies conducted locally and internationally [26, 27]. In 2015, the estimated prevalence of stunting among school aged children in Africa and Asia was 37 and $23 \%$ respectively [28]. Reduction in the prevalence of stunting in recent years shows that substantial improvements are possible as a result of socioeconomic changes along with specific infection control and dietary interventions. This also consistent with United Nations Decade of Action on Nutrition (from 2016 to 2025) aiming to decrease all types of malnutrition [29]. But this needs greater and ongoing efforts to reach low prevalence like countries as turkey [30]. The significant high prevalence of stunting among males agrees with some previous studies [30,31], and disagrees with others [32]. In the current study, increased stunting percentage among males and children aged $\geq 9$ years old; can be explained by the emergence of child labor and its negative effects on their health. The demographic analysis of the results showed higher prevalence of stunting among children with low SES and of rural areas residency. This finding agrees with Sharaf et al. [26] The present study assessed causes of short stature and revealed that non pathological causes were the highest in prevalence and stratified as familial, constitutional, and idiopathic. The hallmarks of familial cause were; an appropriate bone age for chronologic age with normal growth velocity, and predicted adult height was appropriate to the family, in Contrast to constitutional cause which characterized by bone age delay with normal growth velocity and predicted adult height was appropriate to the family, they mostly have relative or parents with late puberty [33]. This agrees with Hussein et al. in Egypt who presented the causes as; non pathological variants represented $61.6 \%$ and most frequent pathological causes were GHD and hypothyroidism and Velayutham $\mathrm{K}$ et al. who showed that familial cause was the most common etiology [22, 34]. but it disagrees with Colaco et al. and Bhadada et al. who reported the prevalence of normal variants to be 20.5 and $15.9 \%$ respectively $[35,36]$. The present study showed that the prevalence of GHD as a pathological cause to short stature was nearly the same as that measured in Hussein et al., Velayutham et al. and Bhadada et al. [22, 34, 36] while the prevalence of hypothyroidism was much lower than that measured in

Table 3 Distribution of height and BMI regarding demographic data among the studied participants

\begin{tabular}{|c|c|c|c|c|c|c|c|c|c|c|c|c|c|c|}
\hline \multirow{4}{*}{$\begin{array}{l}\text { Age (Y) } \\
<9(n=21,989)\end{array}$} & \multicolumn{6}{|c|}{ Height } & \multirow{4}{*}{$\begin{array}{l}P \text { value } \\
<0.001^{*}\end{array}$} & \multicolumn{6}{|l|}{$\underline{B M I}$} & \multirow{4}{*}{$\begin{array}{l}P \text { value } \\
<0.001^{*}\end{array}$} \\
\hline & \multicolumn{2}{|c|}{$\begin{array}{l}\text { Short suture } \\
(\text { No. }=5651)\end{array}$} & \multicolumn{2}{|c|}{$\begin{array}{l}\text { Normal } \\
(\text { No. }=26,221)\end{array}$} & \multicolumn{2}{|c|}{$\begin{array}{l}\text { Tall suture } \\
\text { (No. }=1278)\end{array}$} & & \multicolumn{2}{|c|}{$\begin{array}{l}\text { Underweight } \\
(\text { No. }=2707)\end{array}$} & \multicolumn{2}{|c|}{$\begin{array}{l}\text { Normal } \\
(\text { No. }=23,213)\end{array}$} & \multicolumn{2}{|c|}{$\begin{array}{l}\text { Overweight/ obese } \\
(\text { No. }=7230)\end{array}$} & \\
\hline & no & $\%$ & no & $\%$ & no & $\%$ & & no & $\%$ & No & $\%$ & no & $\%$ & \\
\hline & 3465 & 15.8 & 18,091 & 82.3 & 433 & 1.9 & & 1639 & 7.5 & 15,953 & 72.5 & 4397 & 20.0 & \\
\hline$\geq 9(n=11,161)$ & 2186 & 25.2 & 8130 & 74.5 & 845 & 7.6 & & 1068 & 9.6 & 7260 & 65.0 & 2833 & 25.4 & \\
\hline \multicolumn{15}{|l|}{ Sex } \\
\hline $\mathrm{M}(n=17,143)$ & 3343 & 19.2 & 13,657 & 79.7 & 143 & 0.8 & $<0.001^{*}$ & 2089 & 12.1 & 11,959 & 69.8 & 3095 & 18.1 & $<0.001 *$ \\
\hline$F(n=16,007)$ & 2308 & 14.4 & 12,564 & 78.2 & 1135 & 7.0 & & 618 & 3.9 & 11,254 & 70.3 & 4135 & 25.8 & \\
\hline \multicolumn{15}{|l|}{ Residence } \\
\hline$\cup(n=18,858)$ & 3029 & 16.1 & 15,064 & 79.9 & 765 & 4.0 & $<0.001^{*}$ & 1006 & 5.3 & 12,738 & 67.5 & 5114 & 27.1 & $<0.001^{*}$ \\
\hline $\mathrm{R}(n=14,292)$ & 2622 & 18.3 & 11,157 & 78.1 & 513 & 3.6 & & 1701 & 11.9 & 10,475 & 73.3 & 2116 & 14.8 & \\
\hline \multicolumn{15}{|l|}{ SES } \\
\hline$L(n=3865)$ & 1147 & 29.7 & 2660 & 68.9 & 58 & 1.4 & & 507 & 13.1 & 2658 & 68.8 & 700 & 18.1 & \\
\hline$M(n=24,970)$ & 3996 & 16.0 & 20,561 & 82.3 & 413 & 1.7 & $<0.001^{*}$ & 2200 & 8.8 & 17,342 & 69.5 & 5428 & 21.7 & $<0.001^{*}$ \\
\hline $\mathrm{H}(n=4315)$ & 508 & 11.8 & 3000 & 69.5 & 807 & 18.7 & & 0 & 0.0 & 3213 & 74.5 & 1102 & 25.5 & \\
\hline
\end{tabular}

*: significant $L$ Low, $M$ Middle, $H$ high 
Table 4 Distribution of anemia and anemia with stunting regarding demographic data among the studied participants

\begin{tabular}{|c|c|c|c|c|c|c|c|c|c|c|}
\hline & \multicolumn{4}{|c|}{ Anemia } & \multirow[t]{3}{*}{ OR (CI95\%) } & \multicolumn{4}{|c|}{ Anemia with stunting } & \multirow[t]{3}{*}{ OR (CI95\%) } \\
\hline & \multicolumn{2}{|c|}{$\begin{array}{l}\text { Yes } \\
(\text { No. }=8619)\end{array}$} & \multicolumn{2}{|c|}{$\begin{array}{l}\text { No } \\
(\text { No. }=24,531)\end{array}$} & & \multicolumn{2}{|c|}{$\begin{array}{l}\text { Yes } \\
(\text { No. }=3282)\end{array}$} & \multicolumn{2}{|c|}{$\begin{array}{l}\text { No } \\
\text { (No. = 29,868) }\end{array}$} & \\
\hline & no & $\%$ & No & $\%$ & & no & $\%$ & no & $\%$ & \\
\hline \multicolumn{11}{|l|}{ Age $(Y)$} \\
\hline$<9(n=21,989)$ & 6011 & 27.3 & 15,978 & 72.7 & *1.23 (1.17-1.30) & 1945 & 8.8 & 20,044 & 91.1 & 1.0 \\
\hline$\geq 9(n=11,161)$ & 2608 & 23.4 & 8553 & 76.7 & 1.0 & 1337 & 12.0 & 9824 & 88.0 & *1.40 (1.30-1.51) \\
\hline \multicolumn{11}{|l|}{ Sex } \\
\hline Boy $(n=17,143)$ & 3810 & 22.2 & 13,333 & 77.8 & 1.0 & 1457 & 8.5 & 15,686 & 91.5 & 1.0 \\
\hline Girl $(n=16,007)$ & 4809 & 30.0 & 11,198 & 70.0 & *1.50 (1.43-1.58) & 1825 & 11.4 & 14,182 & 88.6 & *1.39 (1.29-1.49) \\
\hline \multicolumn{11}{|l|}{ Residence } \\
\hline Urban $(n=18,858)$ & 3841 & 20.4 & 15,017 & 79.6 & 1.0 & 1467 & 7.8 & 17,391 & 99.2 & 1.0 \\
\hline Rural $(n=14,292)$ & 4778 & 33.4 & 9514 & 66.6 & *1.96 (1.87-2.06) & 1815 & 12.7 & 12,477 & 87.3 & *1.72 (1.60-1.85) \\
\hline \multicolumn{11}{|l|}{ SES } \\
\hline Low $(n=4315)$ & 1493 & 34.6 & 2822 & 65.4 & *2.54 (2.29-2.82) & 744 & 17.2 & 3571 & 82.8 & *3.32 (2.85-3.88) \\
\hline Moderate $(n=24,970)$ & 6459 & 25.9 & 18,511 & 74.1 & *1.67 (1.53-1.83) & 2310 & 9.3 & 22,660 & 90.7 & *1.63 (1.41-1.87) \\
\hline High $(\boldsymbol{n}=3865)$ & 667 & 17.3 & 3198 & 82.7 & 1.0 & 228 & 5.9 & 3637 & 94.1 & 1.0 \\
\hline
\end{tabular}

*: significant $L$ Low, $M$ Middle, $H$ high

Velayutham et al. and Bhadada et al. [34, 36], which can be explained by the strict and successful neonatal screening program and availability of thyroid investigations in Egypt. In the present study malnutrition caused stunting in $6.8 \%$ of the sample and this is relatively near to reports from other developing countries [36]. The high prevalence of children with short stature rather than malnourished stunted ones; showing that growth in height isn't dependent only on the extent and nature of the diet and stunting is not a synonym of malnutrition [9]. In contrast, other studies didn't report malnutrition as a cause of stunting, because they conducted the study on children in tertiary centers referred from other hospitals where they may have received nutritional intervention [22]. Celiac disease despite representing a low percentage in comparison to other causes, but it is very important to be involved in the primary investigations of stunting, especially that celiac disease was thought, incorrectly, to be rare in Egypt [8, 37]. This finding is closer to Abu-Zekry et al. but far from Assiri et al. [37, 38] In our study prevalence of turner syndrome was $0.3 \%$ among studied group agrees with other study [22] Higher prevalence of turner syndrome was reported in other studies conducted on referred children to tertiary care centers or endocrine clinics which mayn't appropriate to be generalized [39]. Turner syndrome may be presented by stunting without overall stigmata, so it is recommended to include karyotyping in severely stunted female with unexplained growth failure [40]. Underweight prevalence was $8.2 \%$ among studied children which is higher than reports from other national studies in high income countries like United Kingdom but equal to that in low SES countries [41, 42]. SES and ruralurban inequalities in underweight were observed in our study and also have been highlighted by many studies [43-45]. Inequality of income between rural and urban households explains most of the malnutrition gap [44]. Understanding of the nature and the underlying factors behind urban-rural health inequalities may help in designing effective measures for improving population health. Present study reported that about $21.8 \%$ of the children were overweight and obese, it is much close to the global prevalence which has risen dramatically from just 4\% in 1975 to over $18 \%$ in 2016 [7]. Also there is a great improvement in the levels of overweight in comparison to Egypt Demographic and Health Survey 2015 which showed overweight prevalence 35 and $36.6 \%$ in males and females respectively in the same age group [18]. The present study reported that children from families with sufficient income and higher SES have significantly more positive deviation from mean BMI for age Z-score compared with other children. This phenomenon was found also in developing countries, where fatness of children is related to wealth and poor children are struggling with under nutrition [46]. This relation was found to be more complex as in United States and United Kingdom low SES families have higher risk of obesity and overweight $[47,48]$. The high percentage of both under nutrition and overweight was explained by the nutritional scenarios of the developing countries due to socio-economic and demographic transition, dietary habits, lifestyle modification and increasing risks of non-communicable diseases [2]. The present study found that $26 \%$ of the children suffered from 
anemia. It is considered in the moderate category according to classification of public health significance of anemia in populations [49]. This level is close to reported data from WHO, where $25.4 \%$ of children suffered from anemia globally at the same age group but higher than report from demographic health survey 2015 in Egypt $[49,18]$. Concurrent anemia and stunting represented $9.9 \%$ of studied group. This agrees with results from some middle income countries [50]. On the other hand; this is much less than reported from Ethiopia [17]. The high level of co-occurrence of anemia and stunting is highly concerning because each of them are of significant consequences and their co-occurrence is more threating to the children health. $\beta$-thalassemia is a common hematologic disorder in the Mediterranean basin, particularly in Egypt, it has been the most common type of genetic anemia with a carrier rate of about $10 \%$ [51]. Chronic anemia in general has direct and indirect effects on growth. So, further studies are needed to verify causes of anemia in stunted children in Egypt. Present study showed that anemia and anemia with stunting were significantly higher among children from rural areas and who had low SES and this finding is consistent with Egypt health and demographic survey and Abdel Fatah and Nofal, 2012 which can be explained by higher risk of parasitic infestation, low health services and less iron supplementation $[18,52]$. Also Anemia was found to be less frequent among boys which agrees with demographic and health survey 2015 [18].

\section{Conclusion}

This national study reported high prevalence of short stature in addition to underweight, overweight and obesity which characterize the double burden of malnutrition of the low income and developing countries. Based on these results we recommend integration of governmental and non-governmental efforts through health policy and decision makers to achieve the optimal nutrition for populations and individuals. Anemia showed high concurrence with stunting in low SES and rural categories which indicates the great battle against malnutrition. Familial and constitutional causes of short stature were the most prevalent among stunted children. GHD, hypothyroidism, malnutrition, and celiac disease are treatable and frequent conditions that must be considered.

\section{Acknowledgments}

We thank participant children, their guardians, and workers at the included schools for their active participation in our study. The contents of this article and its opinions expressed within are those of the authors.

\section{Authors' contributions}

All persons who meet authorship criteria are listed as authors, and all authors certify that they have participated sufficiently in the work to take public responsibility for the content, including participation in the concept, design, analysis, writing, or revision of the manuscript. Ali M. El-Shafie, Wael A. Bahbah and Kerollos S. Mahrous have the role of getting the idea, performing introduction and discussion sections and final revision. Zeinab A. Kasemy has the role of sharing in getting the idea, performing statistical analysis, writing the methodology and results and final revision. Amal A. Salama and Safa $\mathrm{H}$. Alkalash shared in writing the introduction and discussion and collection of data. Zein A. Omar, Wael A. Bahabh, Kerollos S. Mahrous, Shaimaa M. Hewedy, Nessreen M. Kotb, Heba S. Abd El-Hady, Eman S. Eladawy, Mohamed A. Zeid, Manar E. Abd El Hamid, Emad H. Hemeda, Mohamed A. Elshafie and Esraa A. El meligy received, diagnosed and collected the data. The entire team arranged a health education session to provide explanation about diseases in all matters and how to overcome. The authors read and approved the final manuscript.

\section{Funding}

No fund received from any organization.

\section{Availability of data and materials}

The datasets used and/or analysed during the current study are available from the corresponding author on reasonable request. (kerosmn1@gmail. com).

\section{Ethics approval and consent to participate}

The study protocol was reviewed and approved by the institutional research review committee in Faculty of Medicine, Menoufia University (ID:

180112Ped). Official permission letters were obtained and directed to general directors of education whom responsible for the chosen schools, then purpose of the study was explained to all mothers/guardians of the children and those who agreed to participate signed an informed consent to confirm their willingness to participate. After screening, results were shared and discussed with mother(s)/guardian(s) who were informed about management plan for their children conditions with encouraging them to follow up their children conditions with their family and pediatric physicians.

\section{Consent for publication}

Consents for publication were obtained from participants parents.

\section{Competing interests}

The authors declare that they have no competing interests.

\section{Author details}

'Department of Pediatrics, Faculty of Medicine, Menoufia University, Shebin El-Koum, Egypt. ${ }^{2}$ Department of Public Health and Community Medicine, Faculty of Medicine, Menoufia University, Shebin El-Koum, Egypt. ${ }^{3}$ Family Medicine Department, Faculty of Medicine, Menoufia University, Shebin El-Koum, Egypt. ${ }^{4}$ Shebin El-Koum, Menoufia, Egypt. ${ }^{5}$ Ministry of Health Hospitals, Cairo, Egypt.

Received: 17 April 2020 Accepted: 22 June 2020

Published online: 29 June 2020

\section{References}

1. Shrimpton R, Rokx C. The double burden of malnutrition: a review of global evidence: World Bank, World Health Organization; 2012. https://doi.org/10. 1596/27417.

2. World Health Organization. The double burden of malnutrition: policy brief Geneva, 2017. https://www.who.int/nutrition/publications/ doubleburdenmalnutrition-policybrief/en/.

3. Tzioumis E, Adair LS. Childhood dual burden of under-and overnutrition in low-and middle-income countries: a critical review. Food Nutr Bull. 2014; 35(2):230-43.

4. World Health Organization. UNICEF/WHO/The World Bank Group joint child malnutrition estimates: levels and trends in child malnutrition: key findings of the 2020 edition. ISBN: 9789240003576 https://apps.who.int/iris/ bitstream/handle/10665/331621/9789240003576-eng.pdf. Accessed 31 Mar 2020.

5. Walker CL, Rudan I, Liu L, Nair H, Theodoratou E, Bhutta ZA, O'Brien KL, Campbell $\mathrm{H}$, Black RE. Global burden of childhood pneumonia and diarrhoea. Lancet. 2013;381(9875):1405-16.

6. Xu S, Xue Y. Pediatric obesity: causes, symptoms, prevention and treatment Exp Ther Med. 2016;11(1):15-20. 
7. World Health Organization. Obesity and overweight: fact sheet n 311 . Geneva: World Health Organization; 2014. p. 2013. https://www.who.int/ news-room/fact-sheets/detail/obesity-and-overweight.

8. Cohen P, Rogol AD, Deal CL, Saenger P, Reiter EO, Ross JL, Chernausek SD, Savage MO, Wit JM, 2007 ISS Consensus Workshop participants. Consensus statement on the diagnosis and treatment of children with idiopathic short stature: a summary of the growth hormone research society, the Lawson Wilkins pediatric Endocrine Society, and the European Society for Paediatric Endocrinology Workshop. J Clin Endocrinol Metabol. 2008;93(11):4210-7.

9. Scheffler C, Hermanussen M, Bogin B, Liana DS, Taolin F, Cempaka PM, Irawan M, Ibbibah LF, Mappapa NK, Payong MK, Homalessy AV. Stunting is not a synonym of malnutrition. Eur J Clin Nutr. 2020;74(3):377-86.

10. El Mouzan Ml, Al Herbish AS, Al Salloum AA, Foster PJ, Al Omer AA, Qurachi MM. Prevalence of short stature in Saudi children and adolescents. Ann Saudi Med. 2011;31(5):498-501.

11. Barstow $C$, Rerucha $C$. Evaluation of short and tall stature in children. Am Fam Physician. 2015;92(1):43-50 Review. PubMed PMID: 26132126.

12. Prendergast AJ, Humphrey $\mathrm{JH}$. The stunting syndrome in developing countries. Paediatr Int Child Health. 2014;34(4):250-65.

13. De Onis M, Branca F. Childhood stunting: a global perspective. Maternal Child Nutr. 2016:12:12-26.

14. Kaplowitz PB. Short stature. In: McInerny TK, editor. Textbook of pediatric care. Washington, DC: American Academy of Pediatrics; 2009. p. 1727-30.

15. McLean E, Cogswell M, Egli I, Wojdyla D, De Benoist B. Worldwide prevalence of anaemia, $\mathrm{WHO}$ vitamin and mineral nutrition information system, 1993-2005. Public Health Nutr. 2009;12(4):444-54.

16. Wieringa FT, Dahl M, Chamnan C, Poirot E, Kuong K, Sophonneary P, Sinuon M, Greuffeille V, Hong R, Berger J, Dijkhuizen MA, Laillou A. The high prevalence of Anemia in Cambodian children and women cannot be satisfactorily explained by nutritional deficiencies or hemoglobin disorders. Nutrients. 2016;7:8. https://doi.org/10.3390/nu8060348 PubMed PMID: 27338454; PubMed Central PMCID: PMC4924189.

17. Mohammed SH, Larijani B, Esmaillzadeh A. Concurrent anemia and stunting in young children: prevalence, dietary and non-dietary associated factors. Nutr J. 2019;18(1):10.

18. El-Zanaty F, Way A. Egypt health issue survey 2015. Cairo: Egyptian Ministry of Health and Population; 2015. https://dhsprogram.com/pubs/pdf/FR313/FR313.pdf.

19. Fahmy SI, Nofal LM, Shehata SF, El Kady HM, Ibrahim HK. Updating indicators for scaling the socioeconomic level of families for health research. J Egypt Public Health Assoc. 2015;90(1):1-7.

20. World Health Organization. Growth reference data for 5-19 years; 2007. Disponível hein: http://www.who.int/growthref/en. p. 2016.

21. World Health Organization. Haemoglobin concentrations for the diagnosis of anaemia and assessment of severity. World Health Organization; 2011

22. Hussein A, Farghaly H, Askar E, Metwalley K, Saad K, Zahran A, Othman HA. Etiological factors of short stature in children and adolescents: experience at a tertiary care hospital in Egypt. Ther Adv Endocrinol Metabol. 2017;8(5):75-80.

23. Nwosu BU, Lee MM. Evaluation of short and tall stature in children. Am Fam Physician. 2008;78(5):597-604 PubMed PMID: 18788236

24. Lin NH, Ranjitkar S, Macdonald R, Hughes T, Taylor JA, Townsend GC. New growth references for assessment of stature and skeletal maturation in Australians. Aust Orthod J. 2006;22(1):1-10.

25. Ambler GR, Fairchild J, Wilkinson DJ. Debate: idiopathic short stature should be treated with growth hormone. J Paediatr Child Health. 2013;49(3):165-9.

26. Sharaf MF, Mansour El, Rashad AS. Child nutritional status in Egypt: a comprehensive analysis of socioeconomic determinants using a quantile regression approach. J Biosoc Sci. 2019;51(1):1-7.

27. Dangour AD, Uauy R. Nutrition challenges for the twenty-first century. Br J Nutr. 2006;96(S1):S2-7.

28. De Onis M, Blössner M, Borghi E. Prevalence and trends of stunting among pre-school children, 1990-2020. Public Health Nutr. 2012;15(1):142-8.

29. United Nations Decade of Action on Nutrition. In: Seventieth session of the United Nations General Assembly, New York, 15-28 September 2015. Agenda item 15 (A70/L.42; http://www.un.org/ga/search/view_doc. asp?symbol=A/70/L.42, accessed 1 February 2017).

30. Gür E, Can G, Akkuş S, Ercan G, Arvas A, Güzelöz Ş, Çifçili S. Is undernutrition a problem among Turkish school children?: which factors have an influence on it? J Trop Pediatr. 2006;52(6):421-6.

31. Oninla SO, Owa JA, Onayade AA, Taiwo O. Comparative study of nutritional status of urban and rural Nigerian school children. J Trop Pediatr. 2007;53(1): 39-43.
32. Chowdhury SD, Chakraborty T, Ghosh T. Prevalence of undernutrition in Santal children of Puruliya district, West Bengal. Indian Pediatr. 2008;45(1): 43-6 PubMed PMID: 18250505.

33. Ranke MB. Towards a consensus on the definition of idiopathic short stature. Hormone Res Paediatr. 1996;45(Suppl. 2):64-6.

34. Velayutham K, Selvan SS, Jeyabalaji RV, Balaji S. Prevalence and etiological profile of short stature among school children in a south Indian population. Indian J Endocrinol Metabol. 2017;21(6):820.

35. Colaco P, Desai M, Choksi CS. Short stature in Indian children: the extent of the problem. Indian J Pediatr. 1991;58(Suppl 1):57-8.

36. Bhadada SK, Bhansali A, RaviKumar P, Kochhar R, Nain CK, Dutta P, Lal S. Changing scenario in aetiological profile of short stature in India-growing importance of celiac disease: a study from tertiary care Centre. Indian J Pediatr. 2011;78(1):41-4.

37. Abu-Zekry M, Kryszak D, Diab M, Catassi C, Fasano A. Prevalence of celiac disease in Egyptian children disputes the east-west agriculture-dependent spread of the disease. J Pediatr Gastroenterol Nutr. 2008;47(2):136-40.

38. Assiri AM. Isolated short stature as a presentation of celiac disease in Saudi children. Pediatr Rep. 2010;18:2.

39. Lashari SK, Korejo HB, Memon YM. To determine frequency of etiological factors in short statured patients presenting at an endocrine clinic of a tertiary care hospital. Pak J Med Sci. 2014;30(4):858-61 PubMed PMID: 25097532; PubMed Central PMCID: PMC4121713

40. Gravholt $\mathrm{CH}$, Andersen NH, Conway GS, Dekkers OM, Geffner ME, Klein KO, Lin AE, Mauras N, Quigley CA, Rubin K, Sandberg DE. Clinical practice guidelines for the care of girls and women with Turner syndrome: proceedings from the 2016 Cincinnati international Turner syndrome meeting. Eur J Endocrinol. 2017;177(3):G1-70.

41. Pearce A, Rougeaux E, Law C. Disadvantaged children at greater relative risk of thinness (as well as obesity): a secondary data analysis of the England National Child Measurement Programme and the UK millennium cohort study. Int J Equity Health. 2015;14(1):61.

42. Smith S, Craig LC, Raja EA, McNeill G, Turner SW. Prevalence and year-onyear trends in childhood thinness in a whole population study. Arch Dis Child. 2014;99(1):58-61.

43. Regber S, Novak M, Eiben G, Bammann K, De Henauw S, Fernández-Alvira JM, Gwozdz W, Kourides Y, Moreno LA, Molnar D, Pigeot I. Parental perceptions of and concerns about child's body weight in eight $E$ uropean countries-the IDEFICS study. Pediatr Obes. 2013;8(2):118-29.

44. Sharaf MF, Rashad AS. Regional inequalities in child malnutrition in Egypt, Jordan, and Yemen: a blinder-Oaxaca decomposition analysis. Heal Econ Rev. 2016;6(1):23.

45. Gordon D. Inequalities in health: the evidence presented to the independent inquiry into inequalities in health, Chaired by Sir Donald Acheson: Policy Press; 1999. ISBN: 9781861341747.

46. Prentice AM. The emerging epidemic of obesity in developing countries. Int J Epidemiol. 2006;35(1):93-9.

47. Ip P, Ho FK, So HK, Chan DF, Ho M, Tso W, Nelson EA. Socioeconomic gradient in childhood obesity and hypertension: a multilevel populationbased study in a Chinese community. PloS one. 2016;11:6.

48. Shrewsbury $V$, Wardle J. Socioeconomic status and adiposity in childhood: a systematic review of cross-sectional studies 1990-2005. Obesity. 2008;16(2): 275-84.

49. De Benoist B, Cogswell M, Egli I, McLean E. Worldwide prevalence of anaemia 1993-2005; WHO Global Database of anaemia. 2008. ISBN: 97892 4159665 7. https://apps.who.int/iris/bitstream/handle/10665/43894/ 9789241596657_eng.pdf?ua=1.

50. Albalak R, Ramakrishnan U, Stein AD, Van der Haar F, Haber MJ, Schroeder D, Martorell R. Co-occurrence of nutrition problems in Honduran children. J Nutr. 2000;130(9):2271-3.

51. Elmezayen AD, Kotb SM, Sadek NA, Abdalla EM. $\beta$-Globin mutations in Egyptian patients with $\beta$-Thalassemia. Lab Med. 2015;46(1):8-13. https://doi. org/10.1309/LM1AYKG6VE8MLPHG.

52. Abdel Fatah N, Nofal L. Anthropometric status, anemia and intestinal parasitic infections among primary school children in Alexandria, Egypt. J High Inst Pub Health. 2012;42(1):82-102.

\section{Publisher's Note}

Springer Nature remains neutral with regard to jurisdictional claims in published maps and institutional affiliations. 